\title{
Indicators Used in the Energy Sector
}

\author{
F. Martins and C. Felgueiras
}

\begin{abstract}
World energy mix still depends heavily on fossil fuels but the foreseen increase demand, the scarcity of those resources, their unevenly distribution as well as other factors such as economic burdens due to fossil fuel prices and climate change concerns contributed to the establishment and implementation of new policies in the energy sector. Renewable energy sources are being promoted worldwide as a pathway to reduce external energy dependency, moving towards lower carbon energy systems. It is important to policy makers, investors and other stakeholders to have tools for deciding which policies, investments and measures should be implemented in the future. Thus indicators play very important role for fulfilling that task.

This work present a structured presentation of several indicators commonly used to compare solutions in the energy domain.
\end{abstract}

Index Terms-Energy, RES, indicators, sustainability.

\section{INTRODUCTION}

In 2012 the world energy mix still relied heavily on fossil fuels, namely oil, coal and natural gas (Fig. 1). Since 1973 there was a slight reduction on fossil fuels but it is necessary to point out that the energy more than duplicate since then. The percentage of fossil fuels for total primary energy supply was around $82 \%$ in 2012 [1]. One main problem related to these energy sources is the fact that they are not renewable and they will be depleted if today's consumption rate increases or even if continues.

Coal is more abundant then oil or gas and is widely distributed, constituting $65 \%$ of the total of fossil fuel reserves. Main reserves of oil are in the Middle East and the two major reserves of gas are located in the Middle East and in Russia [2].

Another problem is the security of supply since some of these resources, such oil, are located in the Middle East. Concerning gas supply the recent conflict between Russia and Ukraine have increased concerns about gas supply security [3].

Since it is the most abundant fossil fuel and well distributed in the world, coal could be an option however its use stills presents very high environmental impacts.

Nuclear resources although not renewable were seen as an option to some countries. However Chernobyl and more recently the Fukushima accident had led to a shift in many countries that don't want to continue investing in nuclear energy due to the high impacts in case of an accident.

Energy demand is foreseen to increase in the future and electricity is the final form of energy that presents the high

Manuscript received April 20, 2015; revised September 30, 2015.

F. Martins and C. Felgueiras are with the Instituto Superior de Engenharia do Porto (ISEP), School of Engineering, Polytechnic Institute of Porto (IPP), Porto, Portugal (e-mail: \{ffm, mcf $\} @$ isep.ipp.pt). rate of growing but power sector is contributing to the reduction in the share of fossil fuels in this sector [3].

In 2012, the electricity generation was 3.7 higher than in 1973 and in this sector, the mix presents significant changes with a heavy decrease in oil as energy source (see Fig. 2).

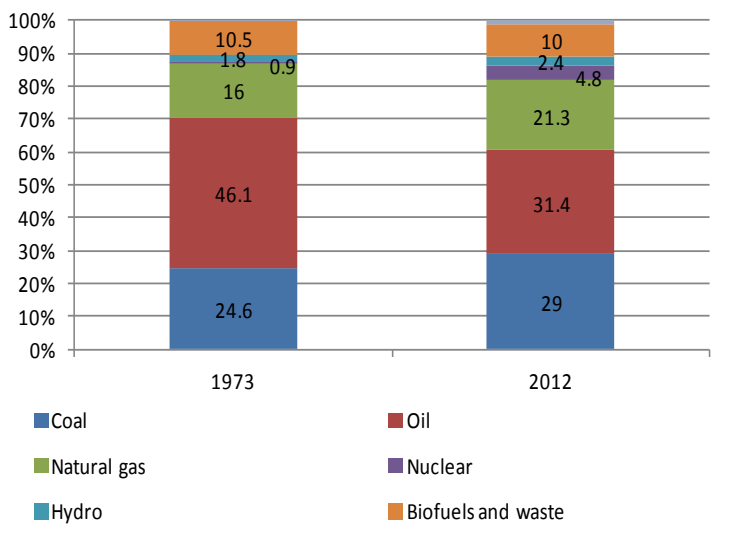

Solar, wind, geothermal, heat,etc.

Fig. 1. Energy mix for energy supply (data from [1]).

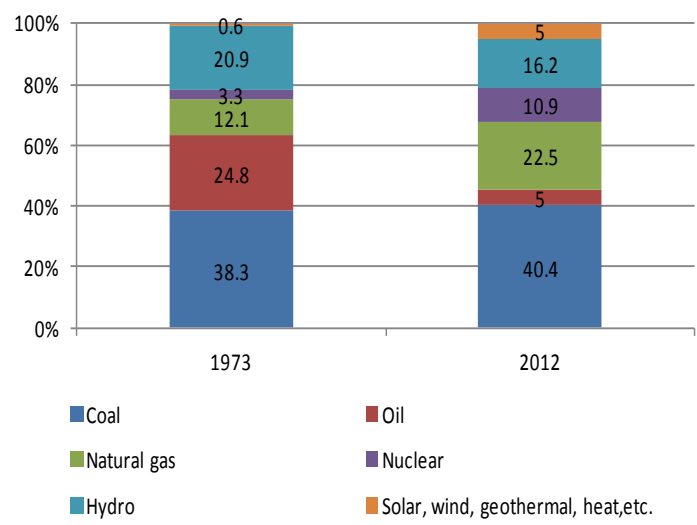

Fig. 2. Energy mix for electricity generation (data from [1]).

In this context Renewable Energy Sources (RES), such as solar, wind, hydropower, geothermal and biomass are being explored worldwide since they are renewable and they are able to contribute to solve the above mentioned problems. Moreover environmental aspects such as global warming are also solved or very attenuated and RES are critical to achieve low carbon energy systems. Energy efficiency is also important to decrease the demand and many efforts are being done in many countries in many fields, transports included [3].

However, renewable energy production and integration poses some economic and technical problems and its deployment has been promoted by governments for example by means of support mechanisms.

In most countries the use of more capital expensive technologies such as the ones associated with RES and the high prices of fossil fuels have increased the costs of electricity to end-user [3]. 
For policy-makers, investors and other stakeholders it is important to have tools to identify which investments should to be done and the advantages and disadvantages of each technology. To carry on adequate decisions indicators play an important role once they define pathways to draw future energy systems. Many indicators are now used in the energy sector, each of them point out different aspects of energy system performance and for that reason it is important to synthesize and organize these indicators in order to better understand and used them.

This work presents the most common energy indicators used in the energy sector and their characteristics.

\section{INDICATORS CRITERIA}

Many authors have been publishing work about indicators for the energy sector. Some of these indicators are base on economical or financial information such as capital costs, operation and maintenance costs, net present value (NPV). Others use environmental information being one the most commonly used the $\mathrm{CO}_{2}$ emissions. Other features also used to define indicators are technical aspects such as efficiency of the technology.

Social indicators can be based on, for example, job creation by production technology or country external energy dependency.

Some of economical, environmental, social or technical indicators follow a life cycle approach considering the life cycle of the project or production technology.

Finally there is the multi-criteria approach combining different indicators to help in the decision-making process. This multi-criteria approach can be developed under sustainability concerns.

\section{ECONOMIC INDICATORS}

In this section some of the economic indicators used will be listed (Table I).

TABLE I: ECONOMIC INDICATORS

\begin{tabular}{|c|l|}
\hline Reference & Indicator \\
\hline$[4]$ & Net present value \\
\hline$[5]$ & Internal rate of return \\
\hline$[6]$ & Return on investment \\
\hline$[6]$ & Payback period \\
\hline$[7]$ & Benefit cost ratio \\
\hline$[4]$ & Capital cost \\
\hline$[4]$ & Operation \& Maintenance costs \\
\hline$[8]$ & Levelised cost of electricity \\
\hline
\end{tabular}

Most of the indicators are generally known being widely used in many areas including energy sector. Net present value, Internal rate of return, Return on investment, Payback period, Benefit cost ratio, Capital cost and Operation \& Maintenance costs fall in this category.

Concerning the levelised cost of electricity (LCOE) it is an indicator that is frequently used for renewable energy projects. The levelised cost of electricity is the average cost over the lifetime of the plant per MWh of electricity generated [9]. Key inputs to calculating LCOE include capital costs, fuel costs, fixed and variable operations and maintenance costs, etc.

In order to established the level of support for RES European Union considers the cost-based approach, namely the levelised cost of electricity as best practice. One important advantage of this method is to make systems more comparable [8].

\section{ENVIRONMENTAL INDICATORS}

In Table II are listed some of the environmental indicators used to assess energy projects.

Due to climate change concerns the first two are often use. Renewable energy is able to reduce greenhouse gas emissions since the use of fossil fuels largely contributes to greenhouse gas emissions.

Other indicators used other pollutant emissions such $\mathrm{SO}_{2}$ and nitrogen oxides.

In what concerns human toxicity some individualized indicators can be considered such as carcinogenics and respiratory effects.

Some of these environmental indicators are often used in a life cycle assessment (LCA) approach. Turconi et al. for example presented a critical review of many cases doing the life cycle assessment of electricity generation on hard coal, lignite, natural gas, oil, nuclear, biomass, hydropower, solar photovoltaic and wind. They considered three life cycle phases namely fuel provision, plant operation and infrastructure and they concluded among other things that greenhouse gas emissions could not be used as a single indicator to represent the environmental performance of a system or technology [10].

\begin{tabular}{cl} 
TABLE II: ENVIRONMENTAL INDICATORS \\
\hline Reference & \multicolumn{1}{c}{ Indicator } \\
\hline$[11]$ & $\mathrm{CO}_{2}$ emissions \\
{$[12]$} & $\mathrm{Greenhouse} \mathrm{gas} \mathrm{emissions}$ \\
{$[13]$} & $\mathrm{SO}_{2}$ emissions \\
{$[13]$} & Nitrogen oxides emissions \\
{$[14]$} & Abiotic depletion \\
{$[14]$} & Ozone layer depletion \\
{$[14]$} & Human toxicity \\
{$[14]$} & Photochemical oxidation \\
{$[14]$} & Acidification \& Eutrophication \\
{$[14]$} & Land occupation \\
{$[15]$} & Water footprint \\
{$[14]$} & Ecotoxicity \\
\hline
\end{tabular}

\section{TECHNICAL INDICATORS}

In this section some of the technical indicators often used will be mentioned (Table III). Some of them are also determined using a life cycle assessment approach such as cumulative energy demand and energy payback ratio. The cumulative energy demand is the ratio between all energy required to build, maintain and supply (includes embedded energy) and the final energy product generated during the life span. The net energy ratio is the inverse of cumulative energy demand [16]. The energy payback time is the length of time a system must operate before it recovers the energy invested throughout its life time. The energy return on energy investment is the ratio between the energy obtained from a system and primary energy invested in upstream activities [17]. Efficiency of technology is a unit less indicator and, when considering nonrenewable plants, is calculated using 
heat rates [18]. Efficiency can also be defined as the electricity generated by power installed and this case it calculates the amount of electricity generated per $\mathrm{kW}$ installed [19], [20]. Usually the power installed depends on the energy to be obtained based on also on site characteristics. This indicator allows verifying the performance of the system. The capacity factor is a unit less ratio between the energy produced for a given period of time and the energy that would be produced if the system was operating at its full capacity for the same period of time.

TABLE III: TECHNICAL INDICATORS

\begin{tabular}{cl}
\hline Reference & \multicolumn{1}{c}{ Indicator } \\
\hline$[21]$ & Cumulative energy demand \\
{$[22]$} & Net energy ratio \\
{$[17]$} & Energy payback time \\
{$[17]$} & Energy return on energy investment \\
{$[22]$} & Efficiency of technology \\
{$[22]$} & Capacity factor \\
{$[20]$} & Efficiency \\
\hline
\end{tabular}

\section{SOCIAL INDICATORS}

In Table IV are presented some social indicators that can be used. Job creation measures the number of jobs created for a given technology during its lifetime.

External energy dependency is the ratio between imported energy and total energy required. Fuel dependency is the ratio between imported fuel and fuel required. Finally, the fuel reserve years are the number of years until full depletion of a given non-renewable resource [22].

\begin{tabular}{cl}
\multicolumn{2}{c}{ TABLE III: SOCIAL INDICATORS } \\
\hline Reference & \multicolumn{1}{c}{ Indicator } \\
\hline$[22]$ & Job creation by technology \\
{$[23]$} & External energy dependency \\
{$[22]$} & Fuel dependency \\
{$[22]$} & Fuel reserve years \\
\hline
\end{tabular}

\section{MULTI-CRITERIA ANALYSIS}

There are many works that use a multi-criteria approach some of them embedded with sustainability concerns [16], [22], [24]. Some of them use an Analytic Hierarchy Process to build their models and others use multi-criteria decision-making (MCDM) methods such as Dominance, Maximin, Lexicographic, TOPSIS (Technique for Order Performance by Similarity to Ideal Solution) and SAW (Simple Additive Weighting). In these works generally are considered indicators from different categories, economic, environmental, technical and social.

\section{CONCLUSIONS}

The energy sector is now facing many challenges due to the scarcity of non-renewable resources, their uneven distribution, the environmental and sustainability concerns. New policies and measures are being implementing worldwide to face a foreseen increase in energy demand and to reduce greenhouse gas emissions. RES deployment and integration is necessary because it allow the exploitation of renewable resources available in the regions contributing to reduce the use of fossil fuels and, in many cases, to the reduction of external energy dependency which in turns increases the security of supply and reduces the economic burden. This can make countries' economies more competitive are less vulnerable to the increasing fossil fuel prices. Besides, it can also create new jobs increasing the welfare of populations. However RES integration in the energy systems poses technical problems that should be address in order to be able to move to low carbon economies. For that reason, indicators are important tools for policy-makers and other practitioners because they help to assess different pathways for the future. The use of the indicators presented allows the establishment of targets and to perform benchmarking analysis.

As demonstrated the indicators considered in this work allow the assessment of energy systems, by considering different criteria namely economic, environmental, technical and social. Some authors already use a set of indicators from different areas (e.g. economic, environmental, etc.) to assess different alternatives. Other authors use a life cycle assessment approach to assess indicators related to energy systems. Overall the use of indicators is able to promote sustainability of energy systems.

\section{REFERENCES}

[1] IEA, Key World Energy Statistics, 2013.

[2] S. Shafiee and E. Topal, "When will fosil fuel reserves be diminished?" Energy Policy, vol. 37, issue 1, pp. 181-189, 2009.

[3] IEA, World Energy Outlok 2014 - Executive Summary, 2014.

[4] K. Emhjellen, M. Emhjellen, and P. Osmundsen, "Investment cost estimates and investment decisions," Energy Policy, vol. 30, pp. 91-96, 2002.

[5] D. L. Talavera, G. Nofuentes, and J. Aguilera, "The internal rate of return of photovoltaic grid-connected systems: A comprehensive sensitivity analysis," Renewable Energy, vol. 35, pp. 101-111, 2010.

[6] A. Atieh and S. Al Shariff, "Case study on the return on investment (ROI) for using energy to power-up house in Saudi Arabia," Sustainable Cities and Society, 2015.

[7] J. Islas, F. Manzini, and M. Martíne, "Cost-benefit analysis of energy scenarios for the Mexican power sector,” Energy, vol. 28, pp. 979-992, 2003.

[8] European Commission, "European commission guidance for the design of renewable support schemes," 2013.

[9] UK Department of Energy \&Climate Change, Electricity Generation Costs, 2012.

[10] R. Turconi, A. Boldrin, and T. Astrup, "Life cycle assessment (LCA) of electricity generation technologies: Overview, comparability and limitations," Renewable and Sustainable Energy Reviews, vol. 28, pp. 555-565, 2013.

[11] Y. Wang and T. Sun, "Life cycle assessment of $\mathrm{CO}_{2}$ emissions from wind power plants: Methodology and case studies," Renewable Energy, vol. 43, pp. 30-36, 2012.

[12] Q. Yang, G. Q. Chen, Y. H. Zhao, Z. Li, and Z. F. Wang, "Energy cost and greenhouse gas emissions of a Chinese solar tower power plant," Procedia Environmental Sciences, vol. 5, pp. 77-80, 2011.

[13] G. Jungmeier, G. Resch, and J. Spitzer, "Environmental burdens over the entire life cycle of a biomas CHP plant," Biomass and Bioenergy, vol. 15 , nos. 4/5, pp. 311-323, 1998.

[14] N. Jungbluth, C. Bauer, R. Dones, and R. Frischknecht, "Life cycle assessment for emerging technologies: Case studies for photovoltaic and wind power," Int. J LCA, pp. 1-11, 2004.

[15] S. Hadian and K. Madani, "A system approach to energy sustainability assessment: Are al renewable really green?" Ecological Indicators, vol. 52, pp. 194-206, 2015

[16] I. S. Modahl, H. L. Raadal, L. Gagnon, and T. H. Bakken, "How methodological issues affect the energy indicator results for different electricity generation technologies," Energy Policy, vol. 63, pp. 283-299, 2013.

[17] K. P. Bhandari, J. M. Collier, R. J. Ellingson, and D. S. Apul, "Energy payback time (EPBT) and energy return on energy invested (EROI) of solar photovoltaic systems: A systematic review and meta-analysis," 
Renewable and Sustainable Energy Reviews, vol. 47, pp. 133-141, 2015.

[18] E. W. Stein, "A comprehensive multi-criteria model to rank electric energy production technologies," Renewable and Sustainable Energy Reviews, vol. 22, pp. 640-654, 2013.

[19] F. Martins, C. Felgueiras, and M. Smitkova, "RES efficiency indicator for Portugal, Slovakia and Czech Republic," in Proc. International Conference Renewable Energy Sources, Tatranské Matliare, Slovakia, 2014.

[20] F. Martins and C. Felgueiras, "RES efficiency indicators," Journal of Clean Energy Technology, vol. 3, no. 4, pp. 261-264, 2015.

[21] D. Gurzenich and H. J. Wagner, "Cumulative energy demand and cumulative emissions of photovoatics production in Europe," Energy, vol. 29, pp. 2297-2303, 2004.

[22] G. Burgess and J. G. Fernández-Velasco, "Materials, operational energy inputs, and net energy ratio for photobiological hydrogen Production," International Journal of Hydrogen Energy, vol. 32, pp 1225-1234, 2007.

[23] D. K. Jonsson, B. Johansson, A. Mansson, L. J. Nilsson, M. Nilsson, and H. Sonnsjo, "Energy security matters in the EU energy roadmap," Energy Strategy Reviews, vol. 6, pp. 48-56, 2015.

[24] S. J. W. Klein and S. Whalley, "Comparing the sustainability of U.S. electricity options through multi-criteria decision analysis," Energy Policy, vol. 79, pp. 127-149, 2015.

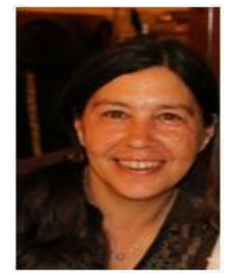

Florinda Martins has a $\mathrm{PhD}$ degree in chemical and biological engineering, a master degree in environmental engineering and a degree in chemical engineering from the Faculty of Engineering, University of Porto, Porto, Portugal, obtained in 2007 , 1998 and 1989, respectively. She has also worked in industry and nowadays is an adjunct professor at Instituto Superior de Engenharia do Porto (ISEP), School of Engineering, Polytechnic Institute of Porto (IPP), Porto, Portugal. Her research interests include sustainability, environment, energy and optimization.

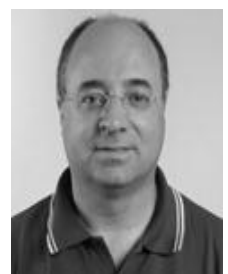

Manuel Carlos Felgueiras received the B.S. and $\mathrm{Ph} . \mathrm{D}$. degrees in electrical and computer engineering from the Faculty of Engineering, University of Porto, Porto, Portugal, in 1987 and 2008, respectively. He started his activity in 1994 as an assistant professor and later on as an adjunct professor and researcher with the Department of Electrical Engineering, School of Engineering, Polytechnic Institute of Porto (IPP), Porto, Portugal.

His research interests include design for debug and test of mixed-signals, remote experimentation in e-learning and renewable energy sources. 